238, 368 (1960). - 11. KIPNIS, D. M. und C. F. CoRI, J. biol. Chemistry 224, 681 (1957). - 12. Akedo, H. und H. N. ChristenSEN, J. biol. Chemistry 237, 118 (1962). - 13. RANDle, P. J., The hypophyseal growth hormone, nature and actions, S. 413, McGrarv-Hall, New York (1955). - 14. PARK, C. R., D. H. Brown, M. Cornblath, W. H. Daughaday und M. E. Krahi, J. biol. Chemistry 197, 151 (1952). - 15. Ikkos, D., H. LJUNGGREN und
R. Lufr, Acta endocr., K'hvn. 22, 211 (1956). - 16. Ikкos, D., R. Luft und C. A. Gemzell, Acta endocr., K'hvn. 32, 341 (1959). - 17. Biglieri, E. G., C. O. Watuington und P. H. Forsham, J. Clin. Endocr., Springfield 21, 361 (1961). - 18. PALMIERI, G. und D. Ikxos, Acta endocr., K'hvn. 48, 469 (1965). - 19. MeLHuish, A. H. und A. L. Greenbaum, Biochem. J. 78, 392 (1961). 20. Tedeschi, H., J. biophysic. biochem. Cytol. 6, 241 (1959).

\title{
Eine einfache Gelfiltrationsmethode zur routinemäßigen Messung der in vitro-Bindung von markiertem Trijodthyronin an Serumeiweiße
}

\author{
Von R. Gränicher, A. Burger, E. Gfeller und H. Studer \\ Aus den endokrinologischen Laboratorien (Leiter: PD Dr. H. Studer) der Mediqinischen Universitätsklinik, Bern \\ (Direktor: Prof. Dr. F. Wyss)
}

(Eingegangen am 10. Oktober 1966)

\begin{abstract}
Es wird eine vereinfachte Gelfiltrationsmethode zur routinemäßigen Bestimmung der in vitro-Bindung von ${ }^{131}$ I-markiertem Trijodthyronin beschrieben. Der Einfluß einer Reihe von Versuchsbedingungen wie $\mathrm{pH}$, Temperatur und Ionenstärke wurde systematisch untersucht. Durch gezielte Anderung dieser Variablen konnte das "Normalresultat" praktisch beliebig verschoben und damit in einen Bereich gelegt werden, in dem sich die euthyreoten von den hyper- und hypothyreoten Werten am besten abgrenzen lassen. Der entscheidende Einfluß der Versuchsbedingungen auf das Testresultat zeigt u. a., daß mit allen angegebenen Verfahren nicht die tatsächliche relative Verteilung von freiem und gebundenem Trijodthyronin gemessen wird, sondern nur ein von den in vitro-Bedingungen streng abhängiger artifizieller Wert.
\end{abstract}

A simplified gel-filtration method is described for the routine determination of the bound and free I $^{131}$-labelled triiodothyronine in serum. The affects of a number of experimental conditions, like $\mathrm{pH}$, temperature and ionic strength, were systematically investigated. By controlling these variables, the "normal resultt" could be shifted practically as desired. A region could thereby be chosen, in which the values for euthyroidism were separated most markedly from those for hyper- and hypothyroidism. The decisive affect of the experimental conditions on the test results is shown by the fact that all methods give only an artificial value, which depends on the in vitro conditions, and the actual relative distribution of free and bound triodothyronine is never obtained.

Die Schilddrüsenhormone werden nach der Sekretion ins Blut zum weitaus größten Teil an Eiweiße gebunden. Nur etwa $1 \%$ des Thyroxins (, $\left.\mathrm{T}_{4}{ }^{\circ}\right)$ im Blut findet sich in freier, biologisch aktiver Form $(1,2,3)$. Die Bindung folgt dem Massenwirkungsgesetz mit hoher Assoziationskonstante:

$$
\mathrm{T}_{4}+\mathrm{P} \rightleftharpoons \mathrm{T}_{4} \mathrm{P} \quad \mathrm{P}=\text { Protein }
$$

Vorausgesetzt, daß die verschiedenen Bindungsstellen an Serumeiweiß gleich stark sind, gilt in Annäherung (4):

$$
\left[\mathrm{T}_{\mathbf{4}}\right]_{\mathrm{f}}=\mathrm{k} \cdot \frac{\left[\mathrm{T}_{\mathbf{4}}\right]_{\mathrm{t}}}{\left[\mathrm{P}_{\text {ungesättigt } \mathrm{t}}\right]} \quad \begin{aligned}
& \mathrm{f}=\text { frei } \\
& \mathrm{t}=\text { total }
\end{aligned}
$$

Die Schilddrüsenhormone haben eine selektive Affinität für bestimmte Eiweißfraktionen, und zwar für das thyroxinbindende Globulin („TBG“), ein inter $\alpha$ Globulin, für Albumin und thyroxinbindendes Praealbumin (,TBPA"). Die Bindung von Tyroxin ist stärker als die von Trijodthyronin $\left(, \mathrm{T}_{3}{ }^{\mathrm{c}}\right)(5)$. Das Verteilungsmuster der Schilddrüsenhormone im Blut, die physiologische Bedeutùng der einzelnen Vehikelproteine und die physikochemischen Gesetze, die die Bindung bestimmen, sind von zahlreichen Autoren untersucht

Abkürzungen: $T_{4}$ : Thyroxin; $T_{9}$ : Trijodthyronin; $T_{s} 1911$ : mit dem radioaktiven Isotop 1sil markiertes $T_{3}$; TBG: Thyroxin-bindendes Globulin; TBPA: Thyroxin=bindendes Praealbumin; SD: Streuung des Einzelwertes (Standard deviation); SEM: Mittlere Abweichung des Mittelwertes. worden (2,5-10). Die freie Bindungskapazität der Serumproteine hängt vom Funktionszustand der Schilddrüse ab: die Absättigung ist größer bei Hyper-, geringer bei Hypothyreose. Zudem ist wahrscheinlich die Bindungskapazität des TBG bei Hypothyreose gesamthaft erhöht (8). Diese Erkenntnisse können zu diagnostischen Zwecken ausgenützt werden. Wird einem Serum in vitro eine geringe Menge ${ }^{131} \mathrm{I}$-markiertes Trijodthyronin (, $\mathrm{T}_{3}{ }^{131} \mathrm{I}^{\prime \prime}$ ) zugesetzt, so wird der Anteil der eiweißgebundenen Radioaktivität u. a. von der Anzahl der freien Bindungsstellen bestimmt. $\mathrm{Da} \mathrm{T}_{4}$ stärker gebunden wird als $T_{3}$, findet keine nennenswerte Verdrängung statt. Auf dieser Grundlage sind in den letzten Jahren diagnostische Teste in mehreren Spielarten ausgearbeitet worden (11). 1955 berichtete HAMOLSKY über eine Methode, die auf der Inkubation des Gesamtblutes mit $T_{3}{ }^{131} \mathrm{I}$ und Messung des an die Erythrozyten gebundenen Anteils beruhte. Durch Kreuzversuche wurde festgestellt, daß für das Ergebnis das Plasma und nicht die Erythrozyten entscheidend waren (12). Der Test erwies sich als brauchbares Hilfsmittel in der Abklärung von Schilddrüsenerkrankungen $(13,14)$. Andere Autoren verwendeten zur Aufnahme des nicht proteingebundenen $\mathrm{T}_{3}{ }^{131} \mathrm{I}$ anstelle der Erythrozyten Austauschharze $(15,16,17)$ oder die Gelfiltration mit Sephadex (18-21) und erzielten klinisch vergleichbare Resultate. Diese Methoden sind einfacher als das von 
HaMOLSKY beschriebene Originalverfahren. Wir haben bei der Anwendung der Gelfiltration weitere Vereinfachungen ausgearbeitet und verschiedene, die Ergebnisse beeinflussende Faktoren untersucht.

\section{Methodik}

\section{Material}

\section{Trijodtbyronin}

Wir verwenden ein ${ }^{131} \mathrm{I}$-markiertes $\mathrm{T}_{3}$ (Thybon ${ }^{131} \mathrm{I}, \mathrm{Fa}$. Hoechst), dessen spezifische Aktivität beim Eintreffen der Sendung gewöhnlich zwischen 10 und $30 \mathrm{mc}^{131} \mathrm{I} / \mathrm{mg} \mathrm{T}_{3}$ bei einer $\mathrm{T}_{3}$-Konzentration von etwa $12 \mu \mathrm{g} / \mathrm{m} /$ beträgt. Durch Verdünnung mit Propylenglykol und 0,9-proz. $\mathrm{NaCl}$ 1:1 werden Lösungen hergestellt, die (nach Korrektur des physikalischen Zerfalls) am vorausberechneten Tag des Verbrauchs $1,2 \mu \mathrm{c}^{131} \mathrm{I} / \mathrm{m} l$ enthalten. Die Lösungen werden bei $-20^{\circ}$ aufbewahrt, das $\mathrm{T}_{3}{ }^{131} \mathrm{I}$ alle 4 Wochen frisch zubereitet.

\section{Pufferlösung}

Sie wird durch Mischung gleicher Teile folgender zwei Stammlösungen hergestellt: $19,5 \mathrm{mM} \mathrm{KH}^{2} \mathrm{PO}_{4}+250 \mathrm{mM} \mathrm{NaCl}$ und $59,0 \mathrm{mM} \mathrm{Na} 2 \mathrm{HPO}_{4} \cdot 2 \mathrm{H}_{2} \mathrm{O}+250 \mathrm{~mm} \mathrm{NaCl}$. Der Puffer hat bei $22^{\circ}$ ein $\mathrm{pH}$ von 6,75.

\section{Sephadex-Säulen}

1,5 g Sephadex G 25 (Korngröße 20 bis $80 \mu$ ) werden nach den Vorschriften des Herstellers aufbereitet und in ein Plexiglasrohr von $9 \mathrm{~mm}$ Innendurchmesser gegossen. Das Roht ist unten durch ein feines Stahlnetz abgeschlossen, das mit Hilfe von Chloroform aufgeklebt wurde. Die Säulen sind von Wassermänteln umgeben, deren Temperatur auf $30^{\circ}$ eingestellt ist. Auf jede Säule wird mit Hilfe eines Gummischlauchstücks ein gleichdimensioniertes Aufsatzrohr gesetzt, das nur zum Aufpipettieren der Serumprobe entfernt wird.

Das nach dem Durchfluß des Serums im Gel adsorbierte freie $T_{3}$ 131I läßt sich mit $0,5 \mathrm{~N} \mathrm{NaOH}$ auswaschen, und die Säulen können nach Neutralisieren mit Pufferlösung wieder verwendet werden. Wir lassen die Lauge aus einem Hebersystem durch ein dünnes Glasrohr mit Druck einfließen. Durch tiefes Eintauchen des Glasrohres in die Säule wird das Gel aufgeschwemmt. Das hat gegenüber einfachem Durchfließenlassen der Lauge den Vorteil des Zeitgewinns. Außerdem sintern die Säulen ohne Aufwirbeln nach zweibis dreimaligem Gebrauch zusammen und werden unbrauchbar. Wir haben in mehreren Säulen nach über 30 maligem Gebrauch unveränderte Werte bei Prüfung desselben Serums erhalten. Wiedergebrauch der Säulen obne Spülung gibt spätestens vom 3. Versuch an abweichende Resultate.

\section{Arbeitsvorschrift}

$2 \mathrm{~m} /$ Serum werden mit $0,1 \mathrm{~m} l$ der verdünnten (s. o.) $\mathrm{T}_{3}{ }^{131} \mathrm{I}$-Lösung gemischt und unter wiederholtem Schütteln während mindestens $15 \mathrm{Min}$. bei Zimmertemperatur unverschlossen stehen gelassen. Dann werden $0,5 \mathrm{~m} l$ in ein zur Messung im Bohrlochkristall geeignetes Reagenzglas mit flachem Boden gegeben und mit Pufferlösung auf $4 \mathrm{ml}$ ergänzt. Diese Probe dient zur Messung der Gesamtaktivität. Je $0,5 \mathrm{~m} l$ werden auf die trockene Oberfläche zweier Säulen sorgfältig aufpipettiert. Nach Einfließen der Probe läßt man auf jeder Säule $1 \mathrm{~m} l$ Puffer einsickern (Trockenliegen der Säulenoberfläche während einiger Minuten hat auf das Resultat keinen Einfluß). Dann werden weitere $4 \mathrm{~m} l$ Puffer aufgesetzt. Von jetzt an wird das Eluat in einem Reagenzglas mit flachem Boden gesammelt. Die ersten $4 \mathrm{~m} l$ enthalten die ganze Eiweißfraktion des aufgetragenen Serums. Bei zwei Seren einer Versuchsreihe sammeln wir in gleicher Weise eine zweite $4 \mathrm{~m} /$-Fraktion. Diese enthält das freie Jodid (das je nach Charge 5 bis $10 \%$ der $\mathrm{T}_{3}$-Aktivität beträgt) und ist repräsentativ für die ganze Serie.

\section{Messung und Berechnung}

Die Messung der Radioaktivität erfolgt im Bohrlochkristall mit einer Reproduzierbarkeit von $\pm 0,5 \%$. Nach Abzug des Leerwertes errechnet sich der Prozentsatz der in der Proteinfraktion ethaltenen Aktivität wie folgt:

Proteinaktivität $\cdot 100$

$\overline{\text { Gesamtaktivität - Jodidaktivität }}$

\section{Ergebnisse}

Vorversuche

Eine Reihe von Vorversuchen hat $\mathrm{zu}$ folgenden Resultaten geführt:

1. Freies $T_{3}{ }^{131} I$, ohne Serum auf die Säule aufgetragen, wird praktisch vollständig adsorbiert.

2. 131, mit oder ohne Serum aufgesetzt, erscheint vollständig in der zweiten Fraktion des Eluates.

3. Serumeiweiß kann im Eluat quantitativ nachgewiesen werden.

4. Durch Drosselung des Abflusses kann die Durchlaufzeit beliebig verlängert werden, ohne daß das Testresultat oder die unter 1 . bis 3 . erwähnten Voraussetzungen sich ändern.

5. Wird das Eluat in Fraktionen von $0,5-1 \mathrm{~m} l$ aufgefangen, so lassen sich regelmäßig zwei gut abgesetzte Aktivitätsspitzen nachweisen. Daher kann das Eluat ohne Nachteil in zwei größeren Fraktionen aufgefangen werden. Messung und Berechnung werden dadurch stark vereinfacht.

6. Der ${ }^{131} \mathrm{I}$-Gehalt einer $\mathrm{T}_{3}{ }^{131} \mathrm{I}-\mathrm{L}$ ösung (nach Durchfluß durch die Säule) ist für einen gegebenen Versuchstag konstant. Bei größeren Versuchsșerien genügt es deshalb, die Jodidfraktion zweier Serumproben zu bestimmen. Die erhaltene Fraktion (in $\%$ ) ist für die ganze Versuchsreihe repräsentativ. Sie wird von jeder Gesamtaktivität abgezogen.

7. Das Endresultat des Testes ist identisch, wenn die Inkubation des Serums mit $\mathrm{T}_{3}$ 131I bei. Zimmertemperatur oder im Wasserbad bei $37^{\circ}$ erfolgt.

8. Haltbarkeit des ${ }^{131} \mathrm{I}$-markierten $\mathrm{T}_{3}$ : Ein Anhaltspunkt für die Dejodierung des $\mathrm{T}_{3}$ ergibt sich auus der $\mathrm{Zu}$ nahme der Jodidfraktion. Sie betrug beispielsweise bei frischem $\mathrm{T}_{3} 3,6 \%$, nach einem Monat $8 \%$.

9. Einfluß der spezifischen Aktivität: Das $T_{3}{ }^{131}$ I enthält eine ansehnliche Menge kalten $\mathrm{T}_{3}$. Die Bedeutung dieses Faktors wurde durch Zusatz von kaltem $T_{3}$ in Konzentrationen von 1,5 und $4,5 \mu \mathrm{g} \%$ zu gebrauchsfertigen $\mathrm{T}_{3}{ }^{131}$-Lösungen getestet (s. Tab. 1). $\mathrm{Da}$ im $\mathrm{T}_{3}$ 131I-Präparat auch kleine Mengen $\mathrm{T}_{4}$ vorhanden sind, wurden ähnliche Bestimmungen unter Beigabe von kaltem $\mathrm{T}_{4}$ in Konzentrationen von $0,005 \mu \mathrm{g}^{0} \%$, $0,015 \mu \mathrm{g} \%$ und $0,045 \mu \mathrm{g} \%$ durchgeführt (s. Tab. 1).

Tab. 1 .

$T_{2}{ }^{131} \mathrm{I}-\mathrm{Bindung}$ an Serumeiweiße bei Verwendung von verschieden lang gelagerten $T_{3}{ }^{131} I$-Lösungen und bei Zusatz von kaltem $T_{3}$ und $T_{4}$
(Mittelwert aus 3 Bestimmungen bei $30^{\circ}$, Phosphatpuffer pH 7,4)

T, ${ }^{131}$ I-Eiweißbindung in $\%$

$T_{3}{ }^{131}$ frisch

$T_{3}^{3} 1311$ vier Wochen gelagert

$\mathrm{T}_{3}^{3}{ }_{131}$ mit Zusatí von $\mathrm{T}_{3}$ kalt $1,5 \mu \mathrm{g} \%$

$\mathrm{T}_{3}{ }^{131} 1$ mit Zusatz von $\mathrm{T}_{2}$ kalt $4,5 \mu \mathrm{g} \%$

$\mathrm{T}^{3}$, 131 mit mit Zusatz von $\mathrm{T}$. kalt, $0,005 \mu \mathrm{g} \%$

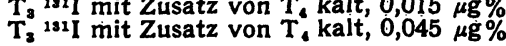

82,0

82,0
82,7
82,3

82,3
83,5

83,5
81,1

$\mathbf{7 9}, \mathbf{8}$

79,1 
10. Konstanz der Werte eines Serumpools: An jedem Testtag werden Proben aus einem eingefrorenen Serumpool mitbestimmt. In 24 Doppelbestimmungen fanden wir einen Mittelwert von 58,5\% und eine Standardabweichung von $\pm 3,2$, Einzelabweichungen bis $5 \%$ kamen vor.

\section{Einflu $\beta$ der Versuchsbedingungen}

Temperatur: Diese wurde mit der früher verwendeten Methode geprüft (Zimmertemperatur, Phosphatpuffer $\mathrm{pH}$ 7,4). Die Resultate sind in Abbildung 1 dargestellt. Ferner wurden Bestimmungen bei verschiedenen Temperaturen und $\mathrm{pH}$ unter Verwendung von $50 \mathrm{~mm}$ Phosphatpuffer durchgeführt, die Resultate sind in Tabelle 2 aufgeführt.

Wasserstoffionenkonzentration: Der Einfluß des $\mathrm{pH}$ des Puffers wurde einerseits bei konstanter Molarität von $50 \mathrm{~mm}$, andererseits bei konstanter Ionenstärke $\mu=0,1$ des Puffers geprüft (s. Tab. 2 u. 3).

Tab. 2

$T,{ }^{131} \mathrm{I}$-Bindung eines Serumpools in \% bei verschiedenen Temperaturen und $\mathrm{pH}$ eines $50 \mathrm{~mm}$ Phosphatpuffers, Mittelwerte aus 3 Bestimmungen

\begin{tabular}{cccc}
\hline pH & $23^{\circ}$ & $30^{\circ}$ & $37^{\circ}$ \\
\hline 6,7 & 85,4 & 75,1 & 68,8 \\
7,0 & 84,4 & 76,8 & 69,9 \\
7,3 & 85,5 & 78,3 & 70,8 \\
7,6 & 86,6 & 80,1 & 74,7 \\
\hline
\end{tabular}

Tab. 3

$T_{3}{ }^{131} \mathrm{I}$-Bindung eines Serumpools in Abhängigkeit vom $\mathrm{pH}$ eines Phosphatpuffers der Ionenstärke 0,1 ; Mittelwerte von 6 Messungen;

\begin{tabular}{cc}
\multicolumn{2}{c}{ SEM $=$ mittlerer Fehler des Mittelwertes } \\
\hline pH & $T_{3}{ }^{131} I-B i n d u n g \% \pm S E M$ \\
\hline 6,7 & $71,8 \pm 0,87$ \\
7,0 & $73,8 \pm 1,49$ \\
7,3 & $72,0 \pm 0,80$ \\
7,6 & $77,3 \pm 1,01$ \\
\hline
\end{tabular}

Ionenstärke: Phosphatpuffer der Ionenstärke $\mu=0,05$ und 0,1 wurde durch Zugabe von $\mathrm{NaCl}$ auf Ionenstärken von 0,$2 ; 0,4 ; 0,8$ und 1,6 gebracht. Das $\mathrm{pH}$ veränderte sich dabei wie folgt:

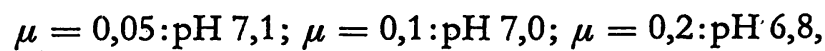
$\mu=0,4: \mathrm{pH} 6,7 ; \mu=0,8: \mathrm{pH} 6,5 ; \mu=1,6: \mathrm{pH} 6,3$.

Ein normaler, ein hypothyreoter und ein hyperthyreoter Serumpool wurden bei $30^{\circ}$ mit diesen Puffern geprüft. Die Ergebnisse sind in Abbildung 2 aufgezeichnet.

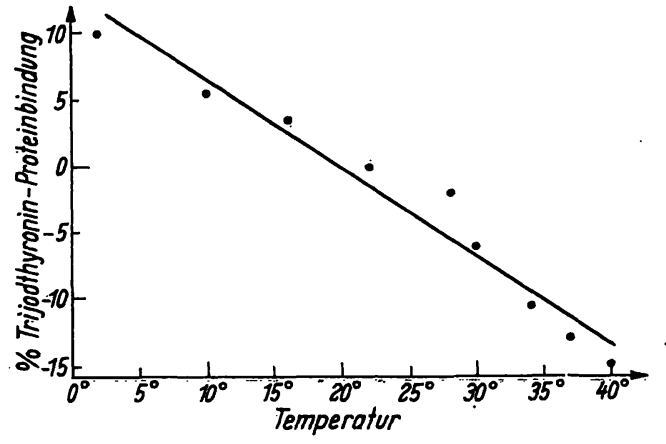

Abb. 1

$T_{3}$ 181I-Bindung in Abhängigkeit von der Temperatur.

Die Resultate sind ais Abweichung vom gleichzeitig bei Zimmertemperatur gefundenen Wert aufgetragen. Es handelt sich um Mittelwerte aus $1-3$ Messungen

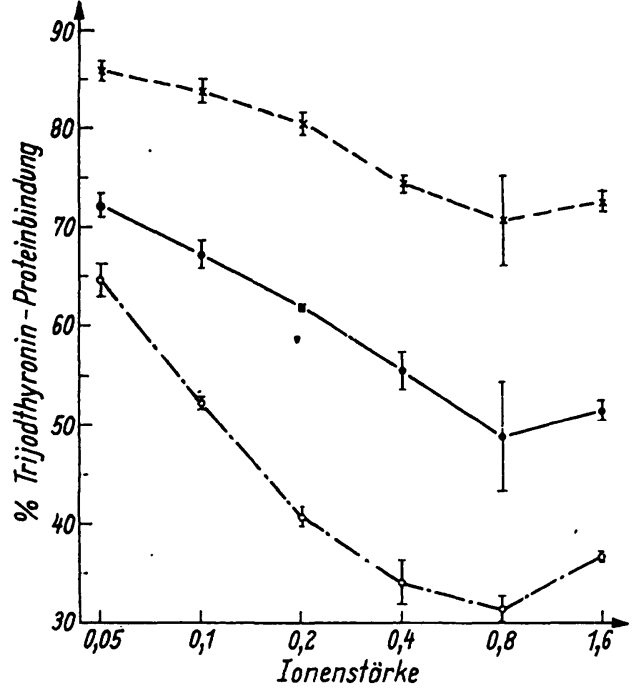

Abb. 2

$\mathrm{T}_{3}{ }^{131} \mathrm{I}$-Bindung in Abhängigkeit von der Ionenstärke. Mittelwerte von 4 Messungen mit Angabe des mittleren Fehlers der Mittelwerte.

Oberste Kurve ( $x-\ldots \ldots-x)$ : hypothyreoter Serumpool Mittlere Kurve $(\mathbf{O}-0):$ euthyrecter Serumpool
Unterste Kurve $(0-0)$ : hyperthyreoter Serumpool

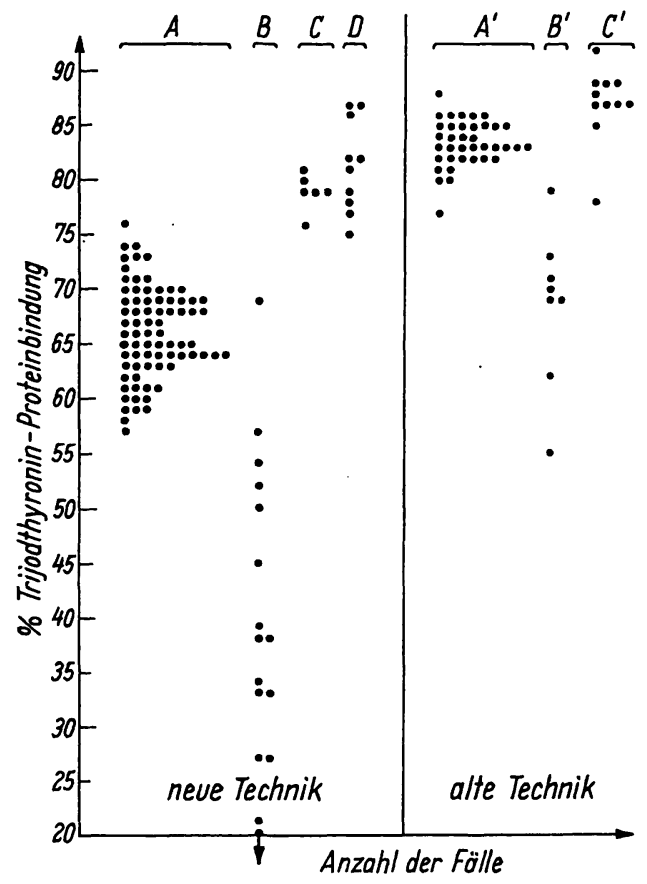

Abb. 3

$T_{3}{ }^{131}$ I-Bindung bei Normalpersonen, Schilddrüsenkranken und Graviden.

Neue Technik: Bestimmung bei $30^{\circ} ; 39,25 \mathrm{~mm}$ Phosphatpuffer, Alte Technik: Bestimmung bei Zimmertemperatur; $50 \mathrm{~mm}$ PhosphatA Normalpersonen; B Hyperthyreosen; $C$ Hypothyreosen; D Graviden

Resultate mit normalen und pathologischen Seren

Normaliverte: Der Normalbereich der Methode wurde aufgrund der Testung von 56 Seren junger, gesunder Spender und von 20 Seren hospitalisierter Patienten ohne klinisch und labormäßig (PBI, z. T. Radiojodaufnahme der Schilddrüse) erfaßbare Schilddrüsenerkrankung ermittelt. Der Mittelwert der Ergebnisse war in den beiden 
Gruppen nahezu identisch. Die an Serumeiweiß gebundene radioaktive $T_{3}$-Fraktion beträgt im Mittel $66,1 \%$ der Gesamtaktivität. Die extremen Einzelresultate liegen bei $57 \%$ und $74 \%$. Die einfache Standardabweichung beträgt $\pm 4,1 \%$. Als ,normal" betrachten wir Ergebnisse, die um weniger als 2 SD streuen $(66,1 \pm 8 \%$ ) (s. Abb. 3).

Hypertbyreosen: Es wurden 16 Seren von Patienten, bei denen klinisch die Diagnose einer Hyperthyreose gestellt worden war, untersucht. $16 \mathrm{mal}$ wurde die Diagnose durch ein erhöhtes PBI gesichert, und $10 \mathrm{mal}$ war ferner eine ${ }^{131}$ I-Traceruntersuchung durchgeführt worden. In allen diesen Fällen war die $\mathrm{T}_{3}{ }^{131} \mathrm{I}$-Eiweißbindung erniedrigt (Abb. 3). Bei einem klinisch hyperthyreoten Patienten mit einem PBI von $8,3 \mu \mathrm{g} / 100 \mathrm{ml}$. (Norm $3,5-8 \mu \mathrm{g} / 100 \mathrm{~m} /$ ) und nicht erhöhtem ${ }^{131} \mathrm{I}-$ Umsatz lag die $\mathrm{T}_{3}{ }^{131} \mathrm{I}$-Bindung des Serumeiweißes im Normbereich $(69 \%)$.

Hy'potbyreosen: Es wurden 4 sekundäre, eine iatrogene (Thiomidilbehandlung) und eine primäre Hypothyreose unbekannter Genese (mit Struma) untersucht. Die Diagnose wurde in allen Fällen durch graphische Registrierung des Achillessehnenreflexes (22) und Messung des PBI gestützt. In vier Fällen wurde zudem der 131I-Umsatz gemessen. Eine Patientin, die bis 2 Wochen vor der Blutentnahme eine Thyroxinsubstitutionsbehandlung erhalten hatte, zeigte ein PBI von $4,1 \mu \mathrm{g} / 100 \mathrm{ml}$. Die $\mathrm{T}_{3}$ 131I-Proteinbindung war durchweg erhöht (Abb. 3).

Gravidität: Die $\mathrm{T}_{3}{ }^{131} \mathrm{I}$-Serumprotein-Bindung wurde bei 10 schwangeren Frauen, und zwar $5 \mathrm{mal}$ bei Graviden der 6. bis 12 . Woche und $5 \mathrm{mal} \mathrm{am}$ Ende der Gravidität untersucht. Die erhaltenen Werte lagen alle im Bereich der Hypothyreose (Abb. 3). Die Eiweißbindung des $T_{3}$ ${ }^{131}$ I betrug im Mittel am Ende der Gravidität $84,6 \pm 1,2 \%$ gegenüber $78,2 \pm 1,4 \%$ bei jüngerer Schwangerschaft.

Östrogenbehandlung: Im Serum einer Patientin, die wegen eines metastasierenden Mammacarcinoms unter Östrogenbehandlung stand und die ein normales PBI und eine normale ${ }^{131} \mathrm{I}$-Clearance aufwies, war die $\mathrm{T}_{3}{ }^{131}$ I-Proteinbindung auf $87 \%$ erhöht. Eine weitere Patientin, ebenfalls mit normalem PBI und normaler Jodaufnahme, die einen Ovulationshemmer einnahm, zeigte ebenfalls eine erhöhte $\mathrm{T}_{3}$ 131I-Bindung an Serumproteine.

Salicylatbehandlung: 10 gesunde jüngere Versuchspersonen nahmen in 24 Stdn. $5 \mathrm{~g}$ Calcium acetylosalicylicum zu sich. Vor dem Versuch und 1 Std. nach der letzten Dosis wurde Blut zur Bestimmung der $\mathrm{T}_{3}$ 131I-Proteinbindung entnommen. Am Ende des Versuchs wurde auch der Salicylatspiegel im Blut bestimmt. Das Ergebnis ist in Tabelle 4 dargestellt. In einem zweiten Versuch wurde 5 Gesunden während 10 Tagen $4 \mathrm{~g}$ Natriumsalicylat über den Tag verteilt gegeben. Vor dem Versuch, am 5. und 10. Tag wurde Blut für dieselben Bestimmungen entnommen. Die Ergebnisse sind in Tabelle 5 zusammengefaßt.

Hypoproteinaemie: Einige Testresultate mit hypoproteinaemischen Seren von Patienten mit verschiedenen Er-
Tab. 4

$T_{2}{ }^{131}$ I-Bindung bei gesunden Personen vor und nach Salicylateinnahme (5 $\mathrm{g}$ in $24 \mathrm{Stdn}$.)

\begin{tabular}{cccc}
\hline Fall & $\begin{array}{c}\mathrm{T}_{\mathbf{3}} \text { 121 I-Proteinbindung in \% } \\
\text { vor } \\
\text { Salicylat- } \\
\text { einnahme }\end{array}$ & $\begin{array}{c}\text { Salicylat } \\
\text { salicylat- } \\
\text { einnahme, }\end{array}$ & $\begin{array}{c}\text { spiegel im } \\
\text { Serum } \\
\text { mg\% }\end{array}$ \\
\hline 1 & 68 & 68 & 14,2 \\
2 & 64 & 66 & 16,6 \\
3 & 72 & 68 & 11,8 \\
4 & 64 & 64 & 15,4 \\
5 & 72 & 67 & 17,8 \\
6 & 64 & 67 & 19,0 \\
7 & 68 & 70 & 17,5 \\
8 & 67 & 69 & 15,8 \\
9 & 66 & 67 & 9,6 \\
10 & 62 & 65 & 17,8 \\
\hline Mittelwert \pm SEM & $66,7 \pm 1,0$ & $67,1 \pm 0,6$ & \\
\hline
\end{tabular}

Tab. 5

$T_{8}{ }^{131} 1$-Bindung im Serum von Gesunden während und nach 10-tägiger Gabe von $4 \mathrm{~g}$ Natriumsalicylat täglich

\begin{tabular}{cccccc}
\hline & \multicolumn{2}{c}{$\mathrm{T}_{\mathbf{2}}$ 181I-Proteinbindung in \% } & \multicolumn{2}{c}{$\begin{array}{c}\text { Salicylatspiegel im } \\
\text { Serum, mg \% }\end{array}$} \\
\hline Fall & vorher & 5. Tag & 10. Tag & 5. Tag & 10. Tag \\
1 & 64 & 63 & 73 & 20,5 & 17,0 \\
2 & 66 & 66 & 73 & 20,5 & 20,0 \\
3 & 65 & 69 & 67 & 11,8 & 17,0 \\
4 & 68 & 71 & 72 & 18,2 & 10,0 \\
5 & 68 & & 69 & & 10,0 \\
\hline Mittelwert & 66,2 & 67,2 & 70,8 & & \\
\pm SEM & $\pm 0,8$ & $\pm 2,0$ & $\pm 1,2$ & & \\
\hline
\end{tabular}

Tab. 6

$\mathrm{T}_{3}$ 131-Bindung bei Hypoproteinaemien

\begin{tabular}{|c|c|c|c|}
\hline Diagnose & $\begin{array}{c}\text { Serumeiwei } \beta \\
\text { (normal: } \\
6-8 \mathrm{~g} \%)\end{array}$ & $\begin{array}{c}\text { PBI } \\
\text { (normal: } \\
3,5-8 \mu \mathrm{g} \%)\end{array}$ & $\begin{array}{c}T_{3}{ }^{281} I- \\
\text { Bindung } \%\end{array}$ \\
\hline \multirow{4}{*}{$\begin{array}{l}\text { Nephrotisches Syndrom } \\
\text { Colitis ulcerosa } \\
\text { vor Colektomie } \\
\text { nach Colektomie } \\
\text { Metastasierendes Magen- } \\
\text { carcinom } \\
\text { Status nach Dünndarm- } \\
\text { resektion }\end{array}$} & 3,7 & & 54 \\
\hline & $\begin{array}{l}4,8 \\
6,3\end{array}$ & $\begin{array}{l}3,4 \\
4,8\end{array}$ & $\begin{array}{l}49 \\
56\end{array}$ \\
\hline & 4,0 & 3,8 & 44 \\
\hline & 4,3 & 4,0 & 61 \\
\hline
\end{tabular}

Tab. 7

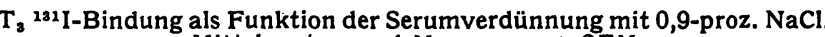
Mittelwerte von 4 Messungen $\pm S E M$

\begin{tabular}{ccc}
\hline \multicolumn{2}{c}{ Serum : NaCi 0,9-proz. } & $\mathrm{T}_{\mathbf{3}}{ }^{\text {1s1 I-Proteinbindung }}$ \\
\hline 1 & 0 & $83,7 \pm 1,2$ \\
3 & 1 & $74,5 \pm 1,2$ \\
1 & 1 & $62,8 \pm 1,5$ \\
1 & 3 & $37,0 \pm 0,6$ \\
\hline
\end{tabular}

krankungen sind in Tabelle 6 zusammengefaßt. Durch Verdünnung des Serums mit 0,9-proz. NaCl-Lösung läßt sich die $\mathrm{T}_{3}{ }^{131} \mathrm{I}$-Bindung erwartungsgemäß vermindern. Ein Serumpool wurde rein und in Mischungen 3:1, 1:1, 1:3 mit 0,9-proz. $\mathrm{NaCl}$ untersucht. Das Resultat ist in Tabelle 7 dargestellt.

\section{Diskussion}

Die Grundlagen der in unserem Laboratorium verwendeten Methode zur Bestimmung des freien und des eiweißgebundenen Anteils von in vitro dem Serum zugegebenen Schilddrüsenhormonen sind schon früher erarbeitet worden. Im deutschen Sprachgebiet ist sie von 2 Gruppen beschrieben worden $(19,21)$. MONGEY und MAson (23) haben auf die in alkalischem Milieu reversible Adsorption von Schilddrüsenhormon an Sepha- 
dex hingewiesen. Die Autoren zeigten ferner, daß Jodid und Dijodtyrosin das Gel passieren. Scriba und Mitarbeiter (21) sind von der früher üblichen Sammlung kleiner Fraktionen auf die sog. „Batch-Technik" übergegangen, die sich bei uns ebenfalls bewährt hat und den Arbeitsaufwand im Routinebetrieb verringert. Im Gegensatz zu SCRIBA und Mitarbeitern bestimmen wir das an Eiweiß gebundene $T_{3}{ }^{131} I$ und das ${ }^{131} I$ in zwei separaten „Batches", im ganzen also mit zwei einzelnen Messungen. Das Verfahren vereinfacht die Bestimmung des freien Jodidanteils im markierten $\mathrm{T}_{3}$ wesentlich.

Die Retention markierter $\mathrm{T}_{3}$-Moleküle im Dextrangel führt $z u$ einem von den Versuchsbedingungen $a b-$ hängigen Gleichgewicht $z$ wischen dem proteingebundenen und dem gelgebundenen $\mathrm{T}_{\mathbf{3}}{ }^{131} \mathrm{I}-$ Anteil. Das Gleichgewicht kann wie folgt beschrieben werden:

$$
\mathrm{Gel} \cdot \mathrm{T}_{3}{ }^{131} \mathrm{I} \rightleftharpoons \mathrm{P} \cdot \mathrm{T}_{3}{ }^{131} \mathrm{I}
$$

Auf dieses Gleichgewicht wirken Faktoren ein, die sowohl die Proteinbindung als auch die Geladsorption beeinflussen können. Die Methode erlaubt also niemals, das tatsächlich im Serum vorhandene "freie" $T_{3}$ quantitativ zu messen.

Mit steigender Temperatur sinkt die Affinität der Serumproteine für markiertes $T_{3}$ in vitro, und es wird eine größere Fraktion an Erythrozyten (24), an Kunstharze $(15,17,25)$ oder an Dextrangel (26) gebunden (Abb. 1). Wir halten deshalb die einzelnen Säulen mit einem Wassermantel von konstanter Temperatur umgeben. Die gewählte Arbeitstemperatur beträgt $30^{\circ}$. Diese Temperatur ist zu jeder Jahreszeit leicht zu halten und verschiebt zudem die Resultate in einen günstigeren Meßbereich. Die Frage des günstigsten Meßbereichs wird später noch eingehender besprochen. Das $p H$ scheint die Proteinbindung zu verändern. Dies geht aus Bestimmungen der Bindungskapazität (27) und aus Dialyseversuchen (28) hervor. Bei hohem $\mathrm{pH}$ ist die Eiweißbindung stärker. Bei unserer Versuchsanordnung fällt dieser Faktor erst bei einem $\mathrm{pH}$ von mehr als 7,3 in Betracht. Die Ionenstärke war für das Resultat unserer Untersuchungen von entscheidender Bedeutung (vgl. Abb. 2). In der Literatur finden sich nur wenig Angaber über den Einfluß dieser Variablen auf die Versuchsresultate. Ein Autor hat auf die Bedeutung der Ionisation für die Trennung von $\mathrm{T}_{4}, \mathrm{~T}_{3}$ und Dijodtyrosin bei Gelfiltration (23), HAMOLSKY und Mitarbeiter haben auf die Rolle der Molarität bei Verwendung von Tris=Puffer für die Verteilung des $T_{3} z$ wischen Serumproteinen und Erythrozyten hingewiesen (27). Bei steigender Molarität stieg die Bindungskapazität des Plasmas, und die Aufnahme an die Erythrozyten sank. Bei unserer Methode verschiebt sich mit steigender Ionenstärke das Gleichgewicht zu Gunsten der Gelbindung. Wie aus den Abbildungen 2 und 3 ersichtlich, hat diese Erkenntnis wesentliche praktische Bedeutung: durch Erhöhung der Ionenstärke, d. h. Beigabe von $\mathrm{NaCl}$ zum Puffer, können die Resultate des Testes in einen Bereich verlegt werden, wo die Abgrenzung der Hyper- und Hypo- von der Euthyreose beträchtlich leichter wird.
Mit der von uns zuerst benutzten Methode (Zimmertemperatur, Phosphatpuffer $50 \mathrm{~mm}, \mathrm{pH} \mathrm{7,4)} \mathrm{fanden} \mathrm{wir}$ es im Gegensatz zu anderen Untersuchern (20) besonders schwierig, die hypothyreoten Werte von den normalen abzugrenzen (vgl. Abb. 3 ,alte Technik"). Der Mittelwert der hypothyreoten Gruppe ist zwar vom Mittelwert der Norm signifikant verschieden $(P<0,001)$, doch war die Bedeutung von Grenzwerten oft unklar. Schon der enge Bereich der hypothyreoten Werte (über $86 \%$ Proteinbindung, wobei Werte über $95 \%$ aus methodischen Gründen nicht zu erwarten sind) ließ von einer Verschiebung der Norm in tiefere Bereiche eine Verbesserung der Auftrennung erwarten. Dies lie $\beta$ sich experimentell begründen (Abb. 2) und durch Untersuchung klinischer Fälle bestätigen (Abb. 3 ,neue Technik"). Die Mittelwerte aller Gruppen sind voneinander mit einem $P<0,001$ verschieden. Von SCRIBA (21) wurde darauf hingewiesen, daß die Säulenlänge das Gleichgewicht ebenfalls verschiebt. Wir haben die Säulenlänge so gewählt, daß eine saubere Abtrennung des eiweißgebundenen $T_{3}{ }^{131} \mathrm{I}$ vom ${ }^{131} \mathrm{I}$ gewährleistet ist.

Durch Veränderung zahlreicher Faktoren läßt sich die Methode so lange manipulieren, bis ein Bereich mit günstiger Abtrennung pathologischer von normalen Werten gefunden ist. Obwohl über die Proteinbindung der Schilddrüsenhormone sehr viele Einzelheiten bekannt sind, bleiben die Vorgänge, die sich bei einer in vitro-Prüfung der Bindungsverhältnisse exogen zugesetzter Schilddrüsenhormone an Serumproteine abspielen, zum großen Teil unklar. Trotzdem hat sich das Prinzip der Methode als sehr wertvoller Test zur Abklärung der Schilddrüsenfunktion längst durchgesetzt. $\mathrm{Zu}$ beachten ist allerdings, daß eine Reihe von Faktoren das Ergebnis fälschen können.

Von praktischer Bedeutung ist z. B. der Einfluß bestimmter Medikamente. Salicylate hemmen die Schilddrüsenfunktion durch einen extrathyreoidalen Mechanismus $(29,30)$. Setzt man dem Serum in vitro Salicylat zu, so wird eine gewisse Menge $\mathrm{T}_{4}$ aus seiner Proteinbindung herausgelöst $(4,31)$. Der Mechanismus dieses Phänomens wird nicht einheitlich beurteilt $(10,32-34)$. In der Literatur finden sich mehrere Hinweise auf die Veränderung der $\mathrm{T}_{3}$-Aufnahmeteste in vitro durch Salicylatmedikation (z. B. 35). Merkwürdigerweise läßt sich mit unserer Methode keine Veränderung der $\mathrm{T}_{3}$ Bindungskapazität von salicylathaltigem Serum nachweisen. Die bei den in Tabelle 5 festgehaltenen Versuchen festgestellte Zunahme der Eiweißbindung ist statistisch nicht signifikant. Man darf den praktischen Schluß ziehen, daß die so häufige unkontrollierte niedrigdosierte Salicylateinnahme den Test nicht fälscht. Bei vielen Patienten ist die Diagnose einer Schilddrüsenerkrankung durch Einnahme organischen Jodes oder organischen Jodids sehr erschwert. Die $\mathrm{T}_{3}{ }^{131} \mathrm{I}$-Aufnahme-Teste scheinen von "Jodverunreinigungen" des Serums unabhängig zu sein (13). Unsere bisherigen Erfahrungen 'mit der Gelfiltration jodhaltiger Seren stimmen mit dieser allgemeinen Erfahrung überein. 
Gewisse Hormone scheinen die Bindungskapazität der Eiweiße für Schilddrüsenhormone zu verändern. Methyltestosteron vermindert die Bindungskapazität (36), Östrogene (24) und ovulationshemmende Hormonpräparate (37) erhöhen sie. In der Schwangerschaft ist die Bindungskapazität ebenfalls wesentlich größer (13, 24,38 ). Die Bestimmung der $\mathrm{T}_{3}$-Bindung mit der Gelfiltration im Serum schwangerer Frauen ergab Resultate, die den erwarteten Ergebnissen entsprachen (s. Abb. 3, Kolonne D). Krankheiten, die zu Veränderungen der Konzentration und Zusammensetzung der Serumeiweiße führen, können die Ergebnisse des $\mathrm{T}_{3}$-Testes beeinflussen. Insbesondere gilt dies von der Hypoproteinaemie, z. B. beim nephrotischen Syndrom (39). Es ist in diesem Zusammenhang von Interesse, daß bei einem unserer Patienten mit Colitis ulcerosa nach Colektomie die Hypoproteinaemie verschwand, und daß sich damit das Testresultat normalisierte. In der Literatur ist eine Verminderung des TBPA bei Leberleiden beschrieben worden (5), eine Angabe, die sich mit Berichten über verminderte $\mathrm{T}_{3}{ }^{131} \mathrm{I}$-Proteinbindung bei Leberaffektionen deckt (39).
Verschiedene Methoden zur Messung der Bindung exogenen Trijodthyronins an Serumeiwei 3 in vitro haben ihre Brauchbarkeit als Kriterien der Schilddrüsenfunktion erwiesen. Mehrere Verfahren sind zu einfachen Routinemethoden geworden. Die Verteilung des radioaktiven Hormons zwischen Eiweißen und adsorbierendem System ist in jedem Falle nur eine Funktion der Versuchsbedingungen und entspricht niemals den tatsächlichen Verhältnissen. Die Versuchsbedingungen können daher nicht beliebig vereinfacht werden, ohne daß die Reproduzierbarkeit der Methode leidet. Andererseits erlaubt es gerade die totale Abhängigkeit der Resultate von den Versuchsbedingungen, den Normbereich solange zu verschieben, bis die bestmögliche Trennung von normalen und pathologischen Zuständen erreicht ist.

Die Arbeit wurde ermöglicht durch die Unterstützung des Schweizerischen Nationalfonds zur Förderung der wissenschaftlichen Forschung. Wir dañken Fräulein E. MAIER, Fräulein CFr. voN GRÜNINGEN und Fräulein R. KUNZ für ihre technische Mitarbeit und Herrn $\mathrm{K}$. BusER für die Bereitstellung und teilweise Neuanfertigung der benötigten Apparaturen.

\section{Literatur}

1. Ref. s. Leading Article, Brit. Med. J. 2, 696 (1963). - 2. RoвBINs, J. und J. E. Rall, Recent Progr. Hormone Res. 13, 161 (1957). - 3. Tata, J. R., Brit. Med. Bull. 16, 142 (1960). - 4. Christensen, L. K., Acta pharmacol. toxicol. ((Köbènhavn) 16,129 (1959). - 5. Britton, A., B. R. Webster, C. Ezrin und R. Volpe, Canad. J. Biochem. 43, 1477 (1965). - 6. Hollander, CH. S., B. H. Latimer, Th. E. Prout, D. H. Lockwood und S. P. Asper, Metabolism 12, 45 (1963). - 7. Hollander, Ch. S., V. V. Odak, Th. E. Prout und S. P. Asper, J. Clin. Endocr., Springfield 22, 617 (1962). - 8. Osorio, C., D. J. JACKson, J. M. GARTSIDE und A. W. G. Goolden, Clin. Sc., London 21, 355 (1961). 9. Sterling, K., Proc. Mayo Clin. 39, 586 (1964). 10. Woeber, K. A. und S. H. INGbar, Endoctinology 73, 118 (1963). - 11. Graul, E. H. und W. StumpF, Dtsch. med. Wschr. 88, 1886 (1963). - 12. Hamolsky, M. W., J. Clin. Invest. 34, 914 (1955). - 13. Hanolsky, M. W., M. Stein und A. S. Freedberg, J. Clin. Endocr., Springfield 17, 33 (1957). - 14. HamoLSKY, M. W., A. Golodetz und A. S. Freedberg, J. Clin. Endoct., Springfield 19, 103 (1959). - 15. GodDEN, J. D. und E. S. GARNEtr, J. Endocr. 29, 167 (1964). - 16. Lie, N. D., V. J. Pileggr und M. Segalove, Clin. Chem. (New York) 10, 136 (1964). 17. Sterling, K. und M. Tabachnick, J. Clin. Endocr., Springfield 21, 456 (1961). - 18. Shapiro, B. und J. L. Rabinowitz, J. nuclear Med. 3, 417 (1962). - 19. StumpF, W. und E. H. Graul, Med. Klinik 58, 192 (1963). - 20. Cuaron, A. und M. E. FucuGANDI, Acta endocr., K'hvn 46, 161 (1964). - 21. SCRIBA, P. C.,
R. Landgraf, H. G. Heinze und K. Schwarz, Klin. Wschr. 44, 69 (1966). - 22. Binswanger, J., H. Studer und F. Wyss, Helvet. med. acta 28, 482 (1961). - 23. Mongey, E. H. und J. W. Mason, Anal. Biochem. (New York) 6, 223 (1963). - 24. Lemarchand, Th. und A. Vanotri, Schweiz. med. Wschr. 93, 7 (1963). 25. Goolden, A. W. G., J. M. Gartside und C. Osorio, J. Clin. Endocr., Springfield 25, 127 (1965). - 26. Murphy, B. E. P. und Ch. J. Pattee, J. Clin. Endocr., Springfield 24, 187 (1964). 27. Hamolsky, M. W., D. B. Fischer und A. S. Freedberg, Endocrinology 66, 780 (1960). - 28. HAMOLSKY, M. W., M. STEIN, D. B. Fischer und A. S. Freedberg, Endocrinology 68,662 (1961). - 29. Austen, F. K., M. E. Rubini, W. H. Meroney und J. Wolff, J. Clin. Invest. 37, 1131 (1958). - 30. WolfF, J. und F. K. Austen, J. Clin. Invest. 37, 1144 (1958). - 31. Christensen, L. K., Nature (London) 183,1189 (1959). - 32. Good, B. F., H. A. Potter und B. S. Hetzeer, Austral. J. exp. Biol. med. Sci. 43, 291 (1965). - 33. Osorio, C., J. Physiology 163, 151 (1962). 34. Wolff, J., M. E. Standaert und J. E. Rall, J. Clin. Invest. 40, 1173 (1961). - 35. Hansen, H. H. und E. F. Mogensen, Acta endocr., K'hvn Suppl. 62, 161 (1962). - 36. FedermanN, D. D., J. Robbins und J. E. RaLL, J. Clin. Invest. 37, 1024 (1958). 37. Florsheim, W. H. und M. A. Faircloth, Proc. Soc. exp. Biol. Med. 117, 56 (1964). - 38. Robrins, J. und J. H. Nelsón, J. Clin. Invest. 37, 153 (1958). - 39. BÉRAUD, T. und A. VANOTTr, Schweiz. med. Wschr. 87, 996 (1957)
Priv.-Doz. Dr. H. Studer CH 3008 Bern, Inselspital 